\title{
Véronique Adam, Images fanées et matières vives. Cinq études sur la poésie Louis XIII
}

\section{Cecilia Rizza}

\section{(2) OpenEdition}

1 Journals

\section{Edizione digitale}

URL: https://journals.openedition.org/studifrancesi/39238

DOI: 10.4000/studifrancesi.39238

ISSN: 2421-5856

\section{Editore}

Rosenberg \& Sellier

\section{Edizione cartacea}

Data di pubblicazione: 1 décembre 2004

Paginazione: 358

ISSN: 0039-2944

\section{Notizia bibliografica digitale}

Cecilia Rizza, «Véronique Adam, Images fanées et matières vives. Cinq études sur la poésie Louis XIII»,

Studi Francesi [Online], 143 (XLVIII | II) | 2004, online dal 30 novembre 2015, consultato il 19 mai 2021. URL: http://journals.openedition.org/studifrancesi/39238 ; DOI: https://doi.org/10.4000/studifrancesi. 39238

Questo documento è stato generato automaticamente il 19 mai 2021.

\section{(c) (1)}

Studi Francesi è distribuita con Licenza Creative Commons Attribuzione - Non commerciale - Non opere derivate 4.0 Internazionale. 


\title{
Véronique Adam, Images fanées et matières vives. Cinq études sur la poésie Louis XIII
}

\author{
Cecilia Rizza
}

\section{NOTIZIA}

VÉRONIQUE ADAM, Images fanées et matières vives. Cinq études sur la poésie Louis XIII Grenoble, ELLUG, Université Stendhal, 2003, pp. 350.

1 La «critique de l'imaginaire», quale è stata teorizzata da Gilbert Durant (ma non mancano riferimenti a Bachelard, Deleuze e J. P. Richard) e ha trovato un terreno di studio privilegiato soprattutto per autori dell'Otto e del Novecento, può essere scelta come strumento di analisi per opere dell'età di Luigi XIII? E in che misura le sue conclusioni confermano, completano o contraddicono nozioni quali Manierismo e Barocco che hanno contribuito alla riscoperta e alla diversa interpretazione di autori francesi di quel periodo? Il progetto dell'Autrice di questo volume è coraggioso e per ciò stesso interessante anche perché mira a identificare un eventuale denominatore comune per scrittori diversi per formazione culturale e sensibilità che si sono espressi in diversi generi letterali. Gli autori presi in esame sono Abraham de Vermeuil, Théophile de Viau, Pierre de Marbeuf, Gabriel Du Bois-Hus e Tristan l'Hermite. Nelle loro opere il processo creativo dell'immaginazione dovrebbe rivelarsi particolarmente significativo nella misura in cui utilizza e trasforma delle immagini e dei miti diventati veri e propri clichés, in quanto elaborati attraverso una lunga tradizione letteraria.

2 Non seguiremo in dettaglio la lettura proposta dall'Adam sui singoli autori. Ricorderemo soltanto che in Abraham de Verneuil viene messo in luce come il gioco delle antitesi e delle pointes manifesti un universo scisso e dilaniato. Più nuova e ardita ci appare 1' interpretazione della poesia di Marbeuf che stabilisce una corrispondenza tra «la rondeur du monde imaginaire de Marbeuf» e «la forme de l'oeil qui porte sur lui 
son regard" (p. 220). Quanto a Du Bois-Hus, mosso da una profonda esigenza di sincretismo, egli porrebbe al servizio della sua ispirazione cristiana e della celebrazione della monarchia le immagini del sole e dell'acqua.

3 Complessa e discutibile l'analisi dell'opera di Théophile de Viau nella quale l'A. dà particolare rilievo a due pièces teatrali: Pasiphaé la cui attribuzione al poeta libertino è molto dubbia, e Pyrame et Thisbé. L'Adam vi riconosce «deux exemples mythiques où les deux sexes se mèlent, où l'intérieur se distingue mal de l'extérieur» cui corrisponde, nella maggior parte delle altre poesie la coincidenza, o meglio la conciliazione degli opposti, resa ancor più manifesta dalla struttura dei componimenti poetici e dai procedimenti retorici adottati . Il significato, o piuttosto i significati diversi che alcune immagini poste sotto il segno dei verbi creuser e couvrir assumerebbero nelle poesie di Tristan ricondurrebbero ad una duplicità che mira non già allo scontro ma alla composizione come ben simboleggia la figura dell'androgino. Così, per vie diverse si viene delineando attraverso l'analisi delle immagini utilizzate, una non dissimile problematica di fondo.

4 Senza mettere in discussione i limiti di questa lettura che, seppur suggestiva, è certamente condizionata dalla scelta di un punto di vista molto particolare, osserveremo soltanto che, stabilendo in conclusione un confronto tra l'opera di questi cinque autori . l'A ritrova, attraverso un percorso critico originale, la presenza di quelle problematiche ideologiche, sociologiche e filosofiche che definiscono storicamente l'età Barocca (in Francia appunto i primi decenni del XVII secolo) e sottendono ad ogni sua interpretazione sul piano strettamente formale. 